\title{
Signal transducer and activator of transcription 3 (Stat3) expression and activation in rat uterus during early pregnancy
}

\author{
Chun-Bo Teng ${ }^{1,2}$, Hong-Lu Diao ${ }^{1}$, Hong Ma ${ }^{1}$, Jing Cong ${ }^{1}$, Hao Yu ${ }^{1}$, Xing-Hong Ma ${ }^{1}$, Li-Bin Xu \\ and Zeng-Ming Yang \\ ${ }^{1}$ College of Life Sciences, Northeast Agricultural University, Harbin 150030, China and ${ }^{2}$ Heilongjiang Fishery \\ Research Institute, Chinese Academy of Fishery Science, Harbin 150070, China
}

Correspondence should be addressed to Zeng-Ming Yang; Email: zmyang@mail.neau.edu.cn

\begin{abstract}
Signal transducer and activator of transcription 3 (Stat3), a member of the Stat family, is specifically activated during mouse embryo implantation. The aim of this study was to investigate the expression, activation and regulation of Stat 3 in rat uterus during early pregnancy, pseudopregnancy, delayed implantation and artificial decidualization. Stat 3 mRNA was highly expressed in the luminal epithelium on day 5 and in the luminal epithelium and underlying stromal cells at implantation sites on day 6 of pregnancy. There was a strong level of Stat3 protein expression and phosphorylation in the stromal cells near the lumen and in the luminal epithelium on day $\mathbf{5}$ of pregnancy, which was similar to day $\mathbf{5}$ of pseudopregnancy. In the afternoon of day 6, the strong level of Stat3 phosphorylation was detected only in the luminal epithelium. Stat3 was highly expressed and activated in the decidual cells from days 7 to 9 of pregnancy and under artificial decidualization in the present study. Our results suggest that the strong level of Stat3 activation in the luminal epithelium and underlying stromal cells during the preimplantation period may be important for establishing uterine receptivity as in mice, and the high level of Stat 3 expression and activation in decidual cells may play a role during decidualization.
\end{abstract}

Reproduction (2004) 128 197-205

\section{Introduction}

Signal transducer and activator of transcription 3 (Stat3), a member of the Stat family, can be activated by a variety of cytokines, including leukemia inhibitory factor (LIF), interleukin (IL)-6, IL-11, oncostatin M, cardiotropin-1, ciliary neurotropic factor, leptin, granulocyte colony-stimulating factor, and epidermal growth factor (Takeda et al. 1997). Stat molecules can be activated by receptor-associated tyrosine kinases through phosphorylation on a single tyrosine residue. After phosphorylation, Stat proteins can form dimers, translocate into the nucleus and activate gene expression by binding to specific response elements in the promoter of target genes (Darnell 1997, Pellegrini \& Dusanter-Fourt 1997).

Stat3 was originally found as the acute phase response factor, a transcription factor activated by IL- 6 and its receptor in liver cells (Akira et al. 1994). Recently, it has been found that many signals relay their effects through Stat3, implicating it in growth, differentiation, survival and apoptosis (Chapman et al. 2000). Although Stat3-deficient embryos could develop into the egg cylinder stage until embryonic day 6.0, these embryos showed a rapid degeneration between embryonic days 6.5 and 7.5 (Takeda et al. 1997). gp130 is a signal-transducing receptor component of LIF, IL-6, IL-11, oncostatin M, cardiotropin1 , and ciliary neurotropic factor receptors (Gearing et al. 1992, Davis et al. 1993). Although gp130-deficient embryos progressively die between 12.5 days postcoitum and term (Yoshida et al. 1996), the mice containing a gp130 mutation which deleted all STAT-binding sites are viable, but have implantation failure in female mice (Ernst et al. 2001). Furthermore, LIF-deficient or IL-11 receptor $\alpha$ deficient mice were unable to support pregnancy due to defective blastocyst implantation and decidua formation respectively (Stewart et al. 1992, Robb et al. 1998).

LIF is highly expressed in the mouse uterus just before implantation (Bhatt et al. 1991, Yang et al. 1995). Embryo implantation failed in LIF-deficient mice (Stewart et al. 1992). In vivo, Stat3 activation is induced by LIF alone, resulting in the localization of Stat 3 specifically to the nuclei of the luminal epithelium on day 4 of pregnancy in mice, coinciding with the onset of uterine receptivity (Cheng et al. 2001). In addition, the activation and nuclear localization of Stat3 in the day-4 luminal epithelium were not detected in any LIF-deficient mice (Cheng et al. 2001), indicating that LIF-induced Stat3 activation is important for mouse implantation. Stat3 expression and activation in the mouse uterus during 
embryo implantation have been examined briefly (Cheng et al. 2001). However, the expression, activation and regulation of Stat3 in rat uterus during early pregnancy are still unknown. The aim of this study was to investigate the expression, activation and regulation of Stat3 in rat uterus during early pregnancy, pseudopregnancy, delayed implantation and artificial decidualization by in situ hybridization and immunohistochemistry.

\section{Materials and Methods}

\section{Animals and treatments}

Mature rats (Sprague-Dawley strain) were caged in a controlled environment (14 h light:10 h darkness). All animal procedures were approved by the Institutional Animal Care and Use Committee of Northeast Agricultural University. Adult females were mated with fertile males of the same strain to induce pregnancy. Pregnancy was confirmed by examining the spermatozoa in vaginal smears (day $1=$ day of positive vaginal sperm). Pregnancy on days 1-5 was confirmed by flushing embryos from the reproductive tracts. The implantation sites on days $6-7$ were identified by tail intravenous injection of $1 \mathrm{ml} 1 \%$ $(\mathrm{w} / \mathrm{v})$ Chicago Blue solution in $0.85 \%(\mathrm{w} / \mathrm{v}) \mathrm{NaCl}$. Pseudopregnancy was induced by co-caging adult females with vasectomized males and was confirmed by checking for a vaginal plug (either in the vagina or on the cage floor) next morning. At least 3 rats were used for each stage or treatment in this study.

To induce delayed implantation, the pregnant rats on day 4 of pregnancy were treated with progesterone $(5 \mathrm{mg} / \mathrm{rat}$, s.c.) and then ovariectomized at $0830-0900 \mathrm{~h}$. Progesterone $(5 \mathrm{mg} / \mathrm{rat})$ was injected to maintain delayed implantation from days 5-7. The progesterone-primed delayed-implantation rats were treated with estradiol- $17 \beta$ $(250 \mathrm{ng} / \mathrm{rat})$ to terminate delayed implantation. The rats were killed by stunning and cervical dislocation to collect uteri $24 \mathrm{~h}$ after estrogen treatment. The implantation sites were identified by tail intravenous injection of $1 \%$ Chicago Blue solution.

Mature female rats were ovariectomized and sensitized for the decidual cell reaction 5 days later according to the procedures described by Kennedy and Ross (1997). Some of the rats were given intrauterine injection of $100 \mu \mathrm{l}$ sesame oil around noon on the equivalent of day 5 of pseudopregnancy. The animals that did not receive the intrauterine injection served as non-stimulated controls (Orlando-Mathur et al. 1996). Treated rats were killed 6 days after the intrauterine injection of oil.

\section{Immunohistochemistry}

Rat uteri were immediately cut into small pieces, fixed in Bouin's solution, dehydrated and embedded in paraffin. Sections $(7 \mu \mathrm{m})$ were cut, deparaffinized and rehydrated. Antigen retrieval was performed by incubating the sections in $1 \mathrm{mM}$ EDTA ( $\mathrm{pH} \mathrm{9.0)}$ ) at $90^{\circ} \mathrm{C}$ for $10 \mathrm{~min}$ and by cooling naturally at room temperature for $20 \mathrm{~min}$. Nonspecific binding was blocked in 10\% normal horse serum in PBS for $1 \mathrm{~h}$. The sections were incubated with rabbit antihuman Stat3 polyclonal antibody (SC-7179, Santa Cruz Biotechnology Inc., Santa Cruz, CA, USA) or rabbit antihuman phospho-Stat3 polyclonal antibody (Tyr-705, SC-7993-R, Santa Cruz Biotechnology) in 10\% horse serum overnight at $4{ }^{\circ} \mathrm{C}$ respectively. After washing in PBS three times for $5 \mathrm{~min}$ each, the sections were incubated with biotinylated goat anti-rabbit $\operatorname{lgG}$, followed by an avidin-alkaline phosphatase complex and Vector Red according to the manufacturer's protocol (Vectastain ABCAP kit, Vector Laboratories, Burlingame, CA, USA). Vector Red was visualized as a red color. Endogenous alkaline phosphatase activity was inhibited by supplementing $1 \mathrm{mM}$ levamisole (Sigma) into Vector Red substrate solution.

Additionally, rabbit anti-human Stat3 or rabbit antihuman phospho-Stat3 was replaced with normal rabbit $\operatorname{lgG}$ as a negative control. The sections immunostained with rabbit anti-human Stat3 were counterstained with hematoxylin and mounted. However, the sections immunostained with rabbit anti-human phospho-Stat3 polyclonal antibody were counterstained with $0.1 \%$ Fast Green containing 10\% glacial acetic acid and 30\% ethanol. The degree of staining was assessed subjectively by blinded examination of the slides by two investigators.

\section{In situ hybridization}

Total RNAs from the mouse uterus on day 7 of pregnancy were reverse-transcribed and amplified with forward primer 5'-AGGAGGGCAGTTTGAGTC and reverse primer 5'-AGGTTGAAAGTGCAGAGCC designed according to mouse Stat3 (2312 2799 bp, Genbank Accession number U06922). The amplification of Stat 3 cDNA was carried out for 35 cycles at $94^{\circ} \mathrm{C}$ for $30 \mathrm{~s}, 60^{\circ} \mathrm{C}$ for $30 \mathrm{~s}$ and $72{ }^{\circ} \mathrm{C}$ for $45 \mathrm{~s}$. The amplified fragment (486 bp) of Stat 3 was recovered from the agarose gel and cloned into pGEM-T plasmid (pGEM-T Vector System 1, Promega). The orientation of the Stat 3 fragment in PGEM-T plasmid was determined by a combination of the primers for T7, SP6, and mouse Stat3. The cloned Stat 3 fragment was further verified by sequencing. The plasmid containing the Stat 3 fragment was linearized with the appropriate enzymes and labeled. Digoxigenin (DIG)-labeled antisense and sense cRNA probes were transcribed in vitro using a DIG RNA labeling kit (Roche Diagnostics $\mathrm{GmbH}$, Mannheim, Germany).

Rat uteri were cut into $4-6 \mathrm{~mm}$ pieces and flash frozen in liquid nitrogen. Frozen sections $(10 \mu \mathrm{m})$ were mounted on 3-aminopropyltriethoxy-silane (Sigma)-coated slides and fixed in $4 \%$ paraformaldehyde solution in PBS. The sections were washed in PBS twice, treated in $1 \%$ Triton X-100 for $20 \mathrm{~min}$ and washed again in PBS three times. Following prehybridization in a solution of $50 \%$ formamide and $5 \times$ SSC $(1 \times$ SSC is $0.15 \mathrm{M}$ sodium chloride, $0.015 \mathrm{M}$ sodium citrate) at room temperature for 
$15 \mathrm{~min}$, the sections were hybridized in the hybridization buffer $(5 \times \mathrm{SSC}, 50 \%$ formamide, $0.02 \%$ BSA, $250 \mu \mathrm{g} / \mathrm{ml}$ yeast tRNA, $10 \%$ dextran sulfate, $1 \mu \mathrm{g} / \mathrm{ml}$ denatured DIGlabeled antisense or sense RNA probe for Stat 3 ) at $55^{\circ} \mathrm{C}$ for $16 \mathrm{~h}$. After hybridization, the sections were washed in $50 \%$ formamide $/ 5 \times$ SSC at $55^{\circ} \mathrm{C}$ for $15 \mathrm{~min}, 50 \%$ formamide $/ 2 \times \mathrm{SSC}$ at $55^{\circ} \mathrm{C}$ for $30 \mathrm{~min}, 50 \%$ formamide $/ 0.2 \times$ SSC at $55^{\circ} \mathrm{C}$ twice for $30 \mathrm{~min}$ each, and $0.2 \times$ SSC at room temperature for $5 \mathrm{~min}$. After nonspecific binding was blocked in $1 \%$ block mix (Roche Diagnostics) for $1 \mathrm{~h}$, the sections were incubated in sheep anti-DIG antibody conjugated with alkaline phosphatase (1:5000, Roche Diagnostics) in $1 \%$ block mix overnight at $4^{\circ} \mathrm{C}$. The signal was visualized with $0.4 \mathrm{mM} 5$-bromo-4chloro-3-indolyl phosphate and $0.4 \mathrm{mM}$ nitroblue tetrazolium in the buffer containing $100 \mathrm{mM}$ Tris $-\mathrm{HCl}, \mathrm{pH}$ 9.5, $100 \mathrm{mM} \mathrm{NaCl}$ and $50 \mathrm{mM} \mathrm{MgCl}{ }_{2}$. Endogenous alkaline phosphatase activity was inhibited with $2 \mathrm{mM}$ levamisole
(Sigma). All the sections were counter-stained with $1 \%$ Methyl Green in $0.12 \mathrm{M}$ glacial acetic acid and $0.08 \mathrm{M}$ sodium acetate for $30 \mathrm{~min}$. The positive signals for in situ hybridization were visualized as a dark brown color.

\section{Results}

\section{Stat3 mRNA expression during early pregnancy}

There was a low level of Stat3 mRNA expression in the luminal epithelium and a basal level in the circular muscles on day 1 of pregnancy (Fig. 1a). On day 2, a low level of Stat 3 mRNA expression was seen only in the luminal epithelium (Fig. 1b). From days 3 to 4, there was no detectable signal in the uteri (Fig. 1c). On day 5, strong Stat3 mRNA expression was observed in the luminal epithelium (Fig. 1d). On day 6, there were low levels of Stat3 mRNA expression in the stromal cells surrounding the
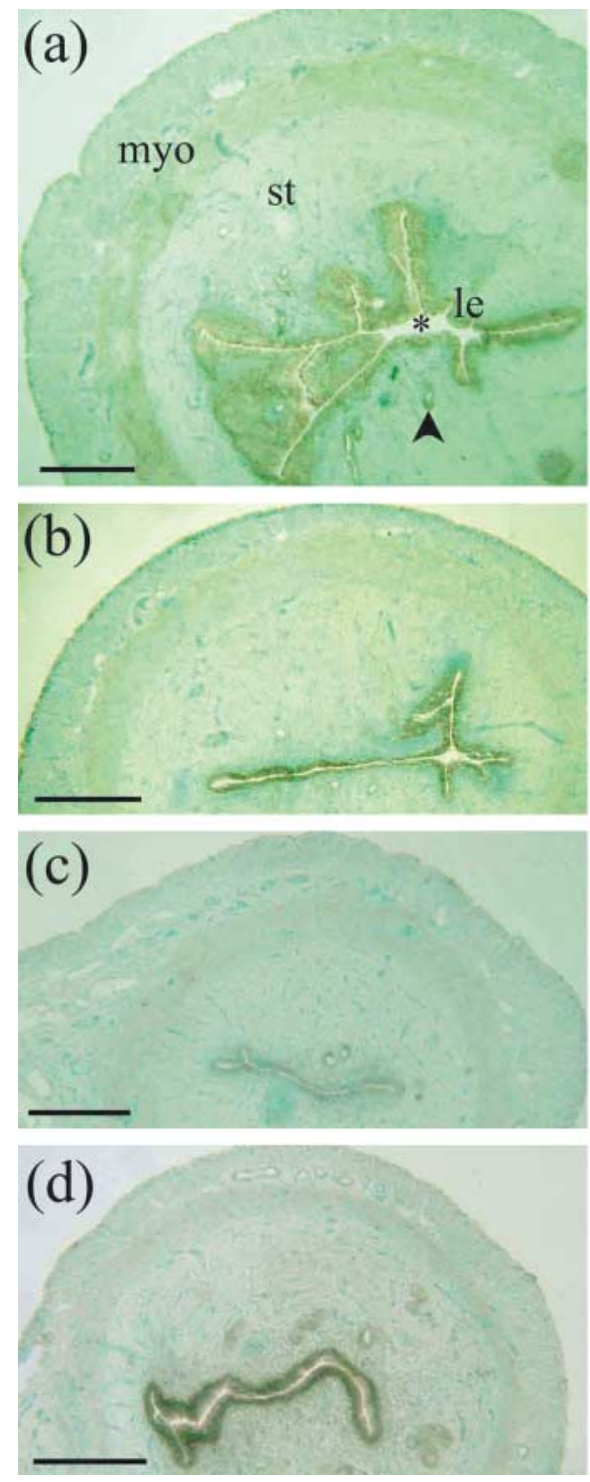
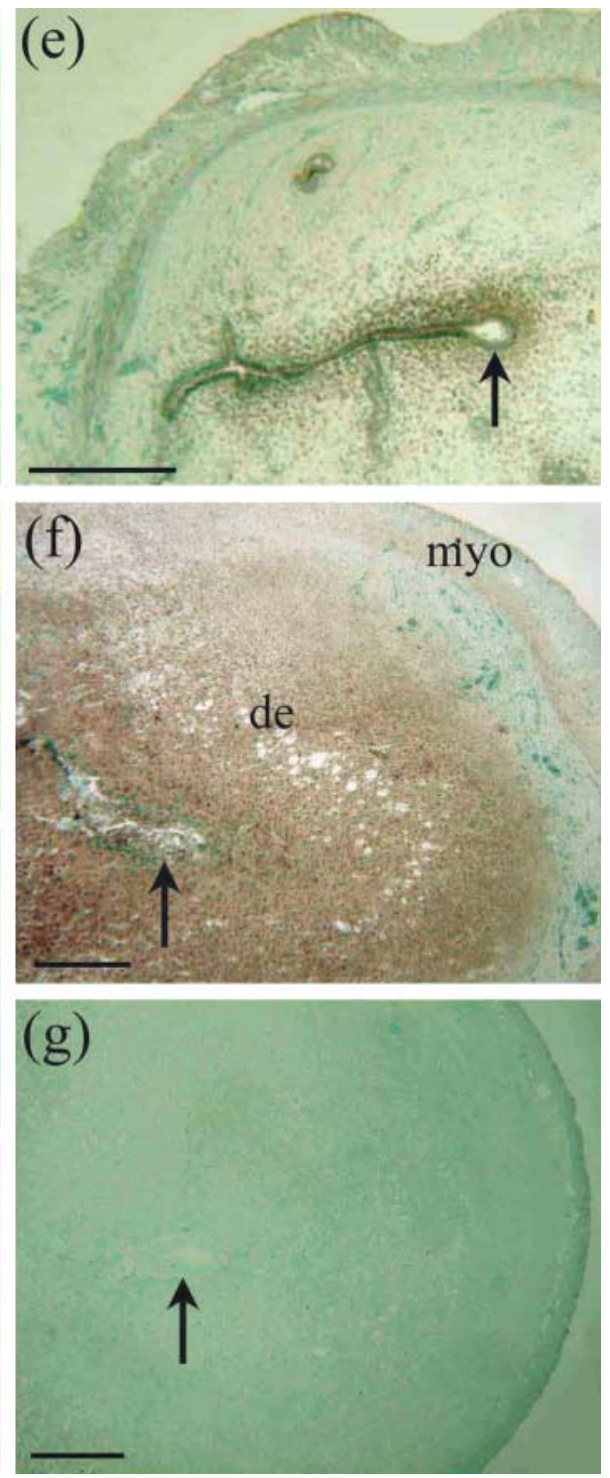

Figure 1 In situ hybridization of Stat3 mRNA in rat uteri during early pregnancy on days 1 (a), 2 (b), 3 (c), 5 (d), 6 (e) and 9 (f). No signals were detected in the uterus on day 9 of pregnancy using the sense probe (g). Arrow, embryo; arrowhead, glandular epithelium; *, uterine lumen; de, decidual cells; le, luminal epithelium; myo, myometrium; st, stroma. Bar $=20 \mu \mathrm{m}$. 

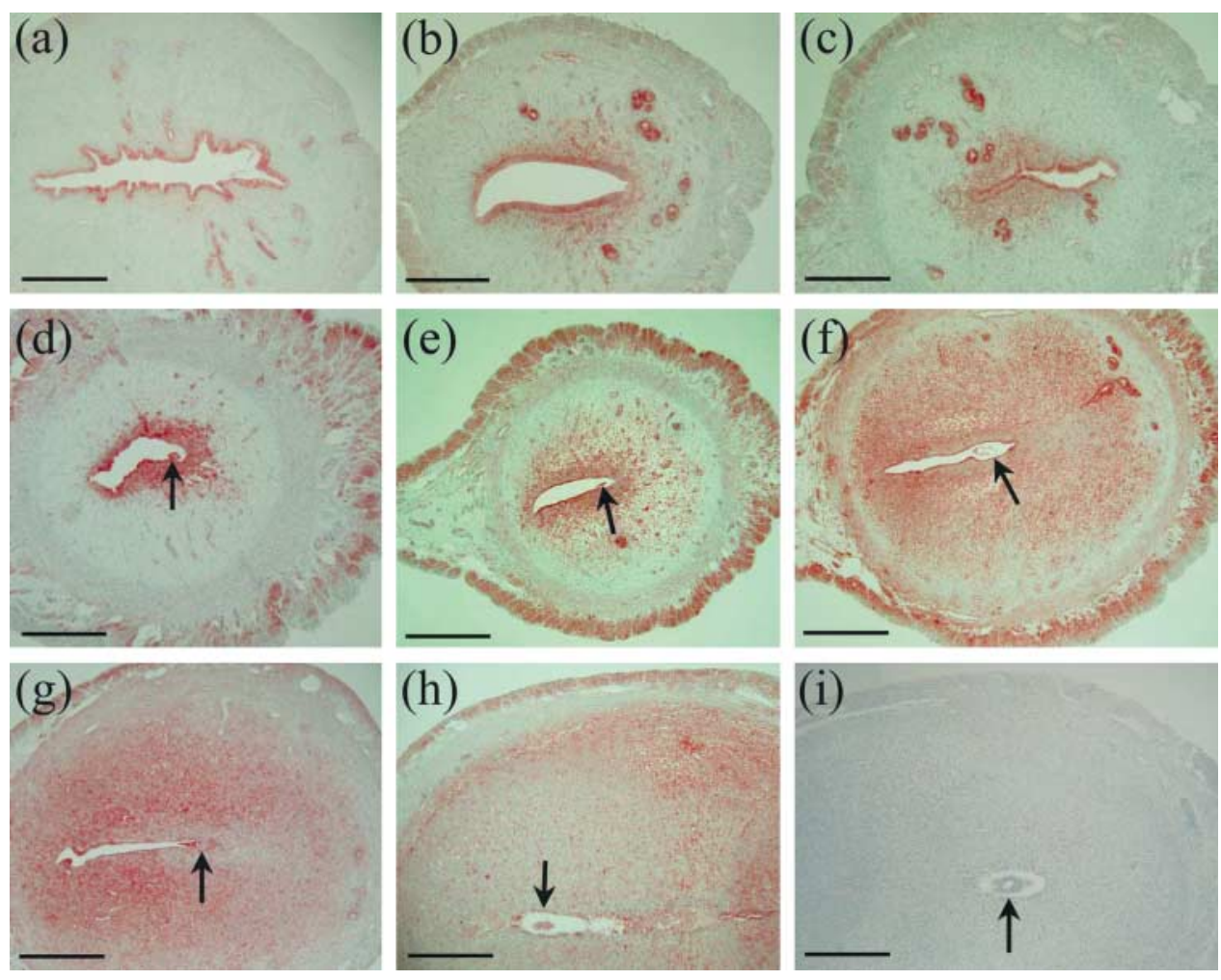

implantation blastocyst and intermediate levels in the luminal epithelium not surrounding the blastocyst (Fig. 1e). From days 7 to 9, strong Stat3 expression was detected in the decidual cells (Fig. 1f). No signals were detected in the uterus on day 9 of pregnancy using the sense probe (Fig. 1g).
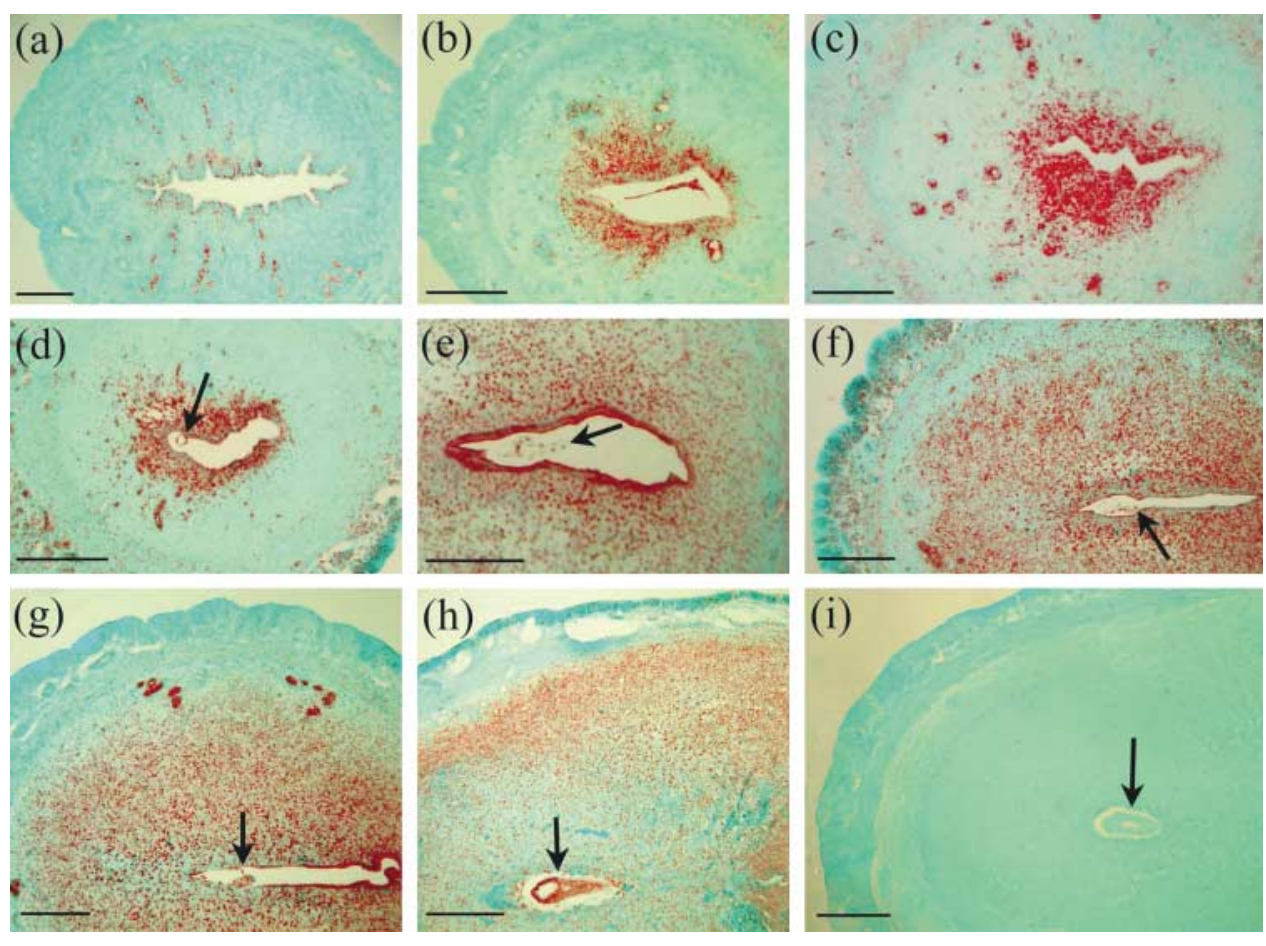
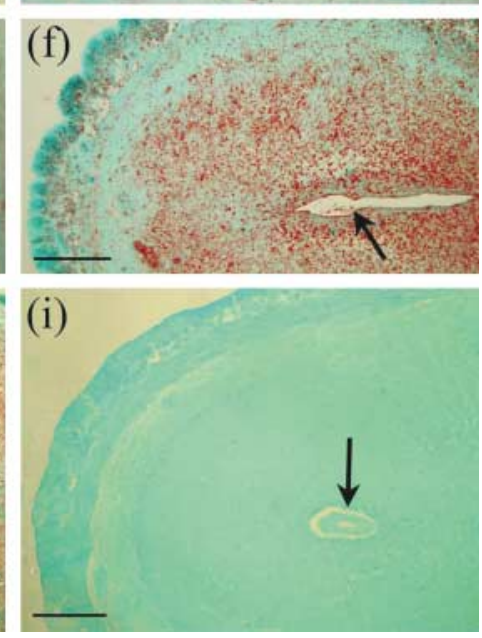

Figure 2 Stat3 immunostaining in rat uteri during early pregnancy on days 1 (a), 4 (b), 5 morning (c), 5 midnight (d), 6 morning (e), 6 midnight $(\mathrm{f}), 7(\mathrm{~g})$ and 9 (h). After rabbit anti-human Stat3 antibody was replaced with normal rabbit IgG, there was no detectable signal in the uterus on day 9 of pregnancy (i). Arrow, embryo.

Bar $=15 \mu \mathrm{m}$.

\section{Stat3 immunostaining during early pregnancy}

There was an intermediate level of Stat3 immunostaining in the luminal and glandular epithelia from days 1 to 3 of pregnancy (Fig. 2a). From day 4 to the morning of day 5, Stat3 immunostaining was at a high level in the glandular

Figure 3 Phospho-Stat3 immunostaining in rat uteri during early pregnancy on days 1 (a), 4 (b), 5 morning (c), 5 midnight (d), 6 afternoon (e), 6 midnight ( $\mathrm{f}), 7$ (g) and 9 (h). After rabbit anti-human phospho-Stat3 antibody was replaced with normal IgG, no signals were detected in the uterus on day 9 of pregnancy (i). Arrow, embryo. Bar $=25 \mu \mathrm{m}$. 
epithelium, and at a low level in the luminal epithelium and the stromal cells near the lumen (Fig. 2b,c). However, at midnight on day $5(2400 \mathrm{~h})$, strong Stat 3 immunostaining was detected in the luminal epithelium and the stromal cells near the implanting blastocyst, and Stat3 immunostaining was also seen in the longitudinal muscle cells (Fig. 2d). On the morning of day 6, Stat3 immunostaining was at an intermediate level in the luminal epithelium, the stromal cells near the implanting blastocyst and the longitudinal muscle cells (Fig. 2e). From midnight on day 6 to day 9 , Stat 3 immunostaining was maintained at a high level in the decidual cells (Fig. $2 \mathrm{f}-\mathrm{h}$ ). After rabbit anti-human Stat3 antibody was replaced with normal rabbit IgG, there was no detectable signal in the uterus on day 9 of pregnancy (Fig. 2i). A high level of Stat3 immunostaining was also seen in the glandular epithelium and the longitudinal muscle cells at midnight of day 6 (Fig. 2f).

\section{Phospho-Stat3 immunostaining during early pregnancy}

From days 1 to 3 of pregnancy, there were high levels of phospho-Stat3 immunostaining in the glandular epithelium and low levels in the luminal epithelium (Fig. 3a). On day 4 , strong phospho-Stat3 immunostaining was detected in the luminal epithelium, the stromal cells and glandular epithelium near the lumen (Fig. 3b). In the morning of day 5, a high level of phospho-Stat 3 immunostaining was seen in the stromal cells near the lumen, the luminal epithelium and the glandular epithelium, while a low level was seen in the myometrial cells (Fig. 3c). At midnight on day 5, there was a high level of phospho-Stat3 immunostaining

\section{Stat3 immunostaining}
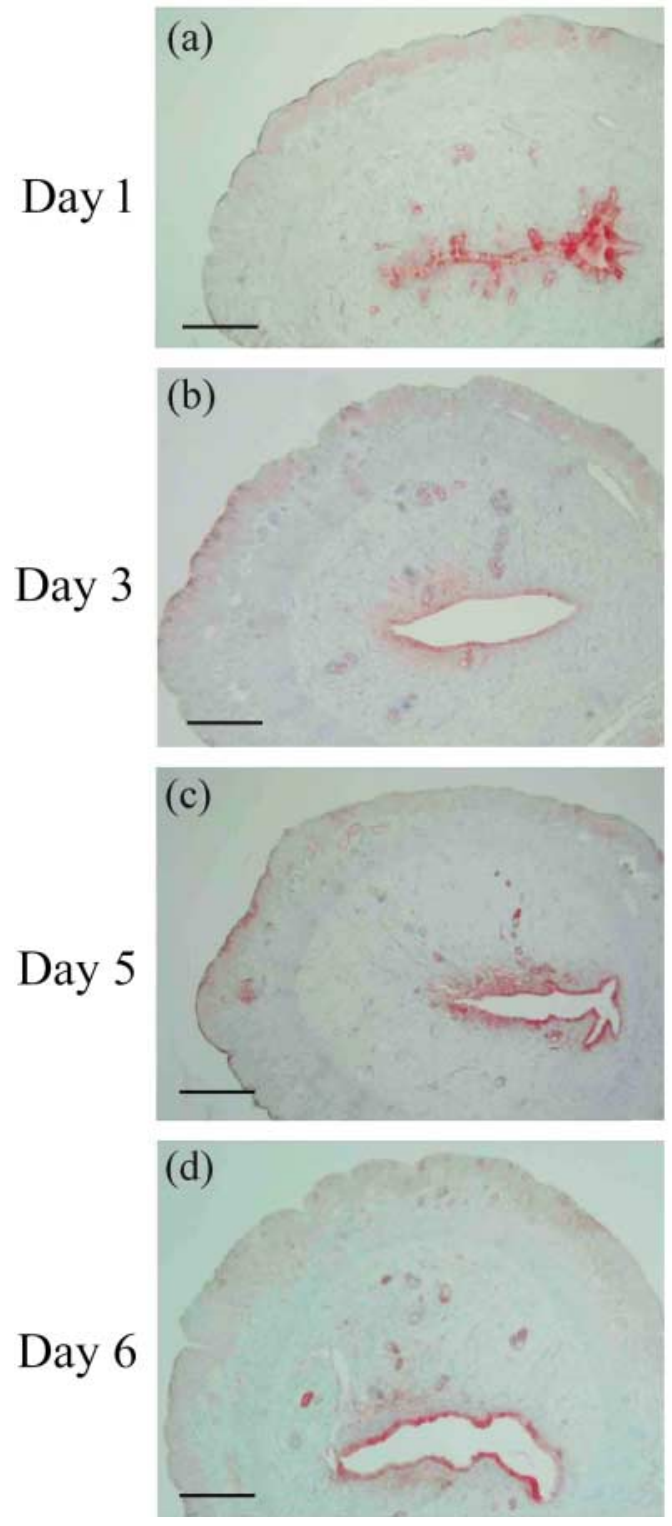

\section{Phospho-Stat3 staining}
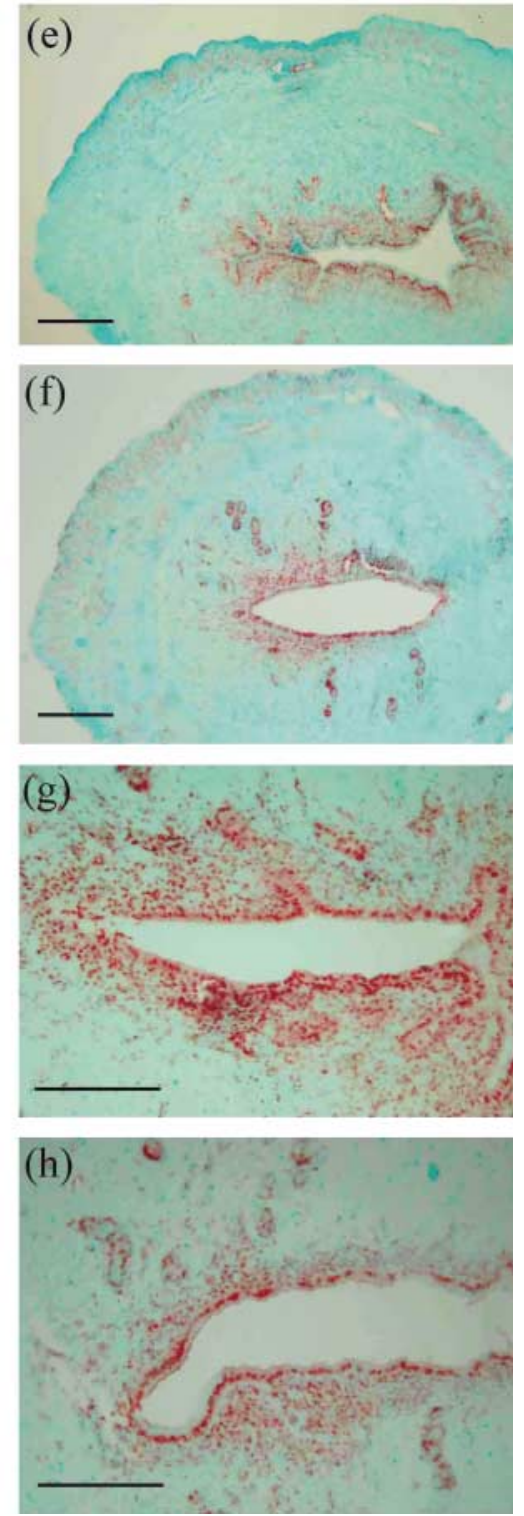

Figure 4 Stat3 immunostaining (left column) and phospho-Stat3 immunostaining (right column) in rat uteri on days 1 (a and e), 3 (b and f), 5 (c and g) and 6 (d and $h$ ) during early pseudopregnancy. The days of pseudopregnancy are labeled at the left side of each row. Bar $=15 \mu \mathrm{m}$. 

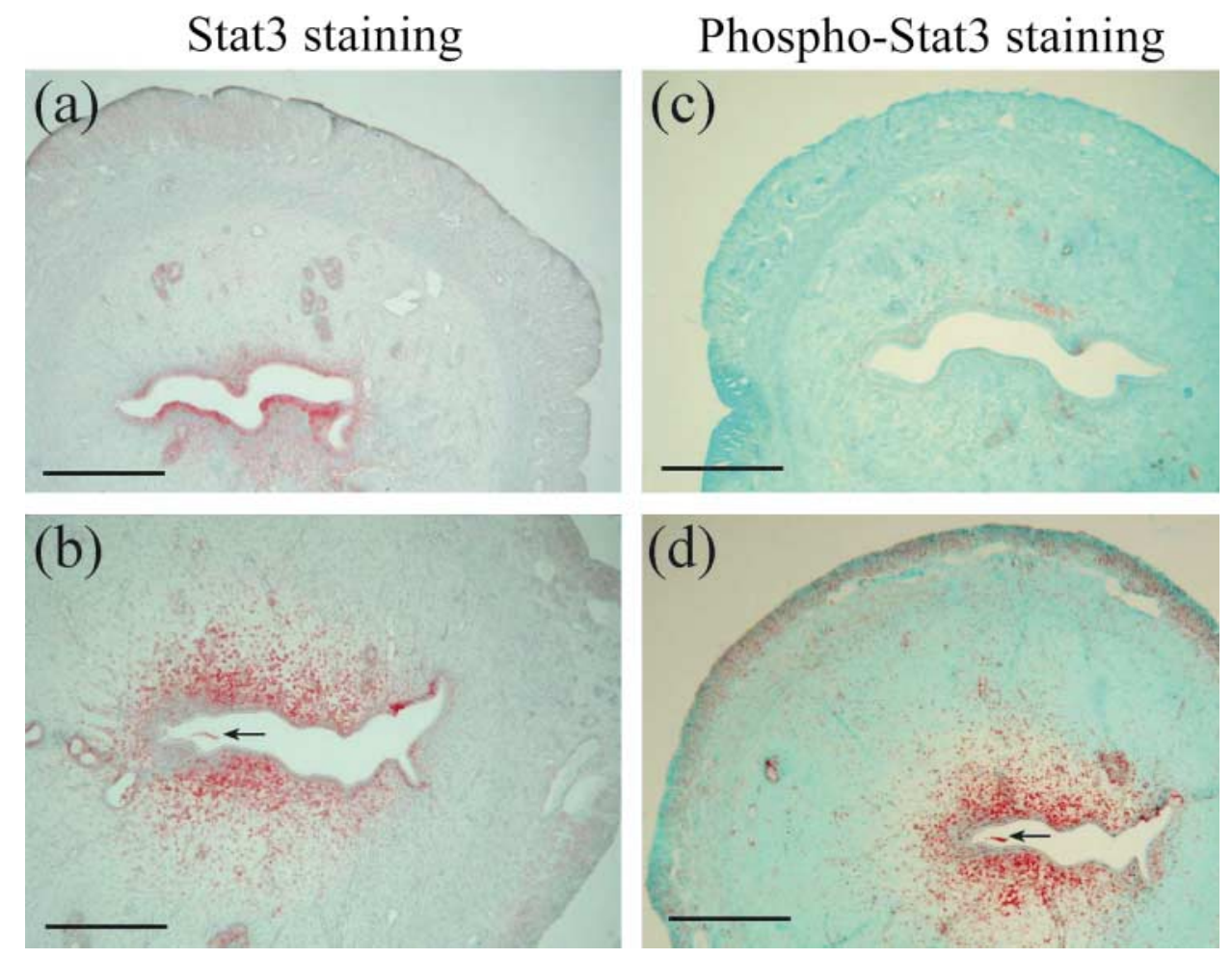

Figure 5 Stat 3 immunostaining (left column) and phospho-Stat 3 immunostaining (right column) in rat uteri under delayed implantation (a and c) and after activation with estrogen treatment ( $b$ and $d)$. Arrow, embryo. Bar $=20 \mu \mathrm{m}$. in the luminal epithelium, the stromal cells and glandular epithelium near the implanting blastocyst, while the levels were low in the longitudinal muscle cells (Fig. 3d). However, the phospho-Stat3 immunostaining in the stromal cells and luminal epithelium decreased to a low level in the morning of day 6 at the implantation site (data not shown). In the afternoon of day 6, strong phospho-Stat3 immunostaining was detected in the luminal epithelium at the implanting site and weak phospho-Stat3 immunostaining was detected in the stromal cells and glandular epithelium (Fig. 3e). At midnight on day 6, strong phospho-Stat3 immunostaining was seen in the decidual cells,

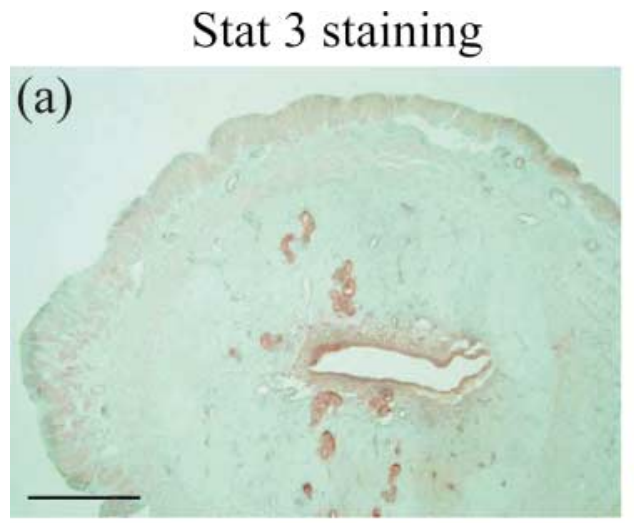

\section{Phospho-Stat 3 staining}
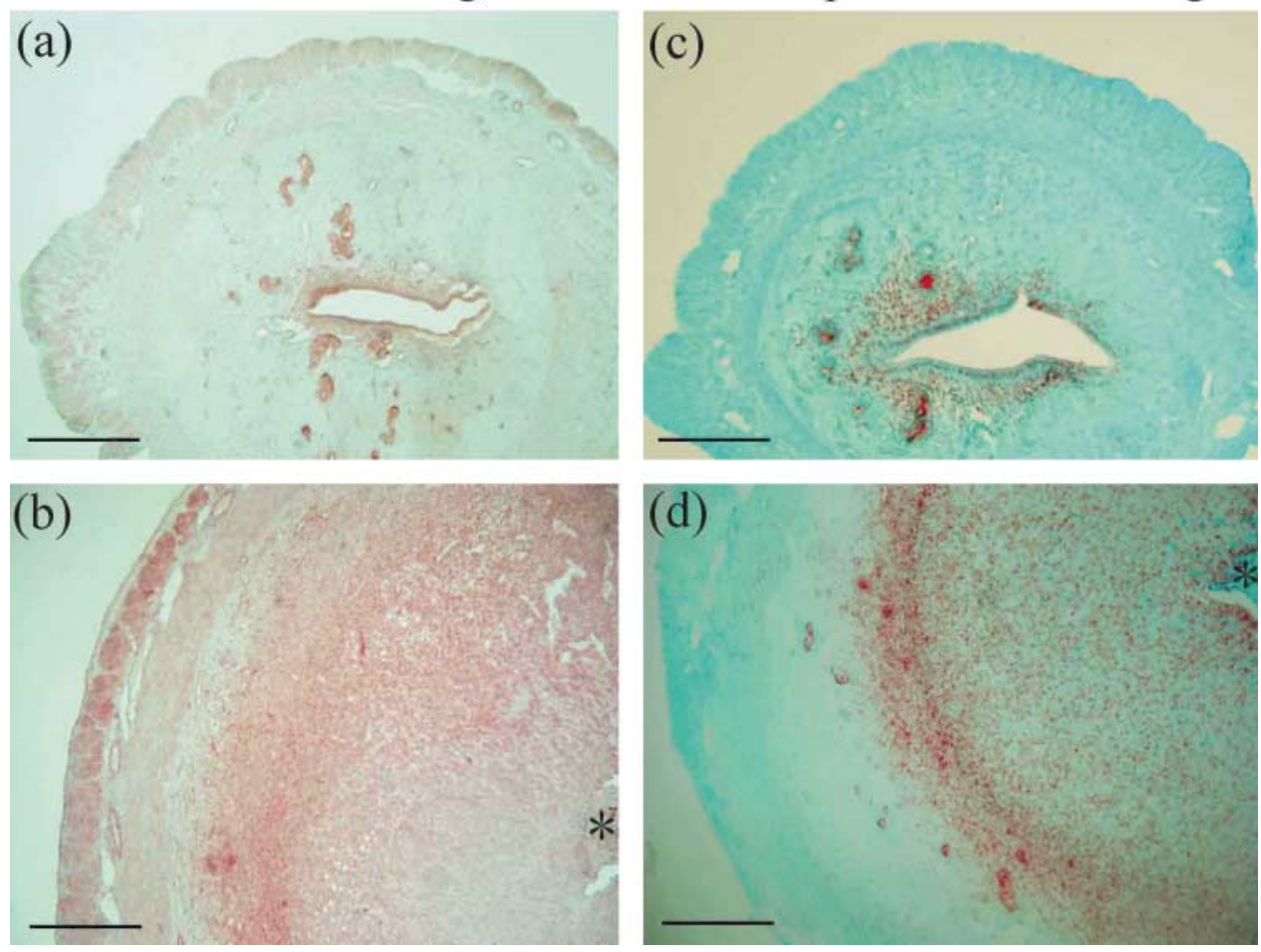

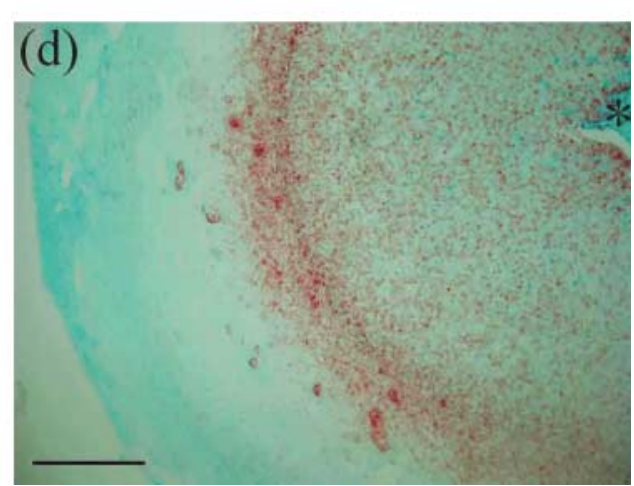

Figure 6 Stat 3 immunostaining (left column) and phospho-Stat3 immunostaining (right column) in rat uteri in the controls (a and c) and under artificial decidualization ( $b$ and $d$ ). *, Uterine lumen. Bar $=20 \mu \mathrm{m}$. 
but not in the luminal epithelium (Fig. 3f). On day 7, strong phospho-Stat3 immunostaining was detected in the decidual cells, glandular epithelium and the luminal epithelium opposite to the implanting blastocyst, but not in the luminal epithelium surrounding the blastocyst (Fig. $3 \mathrm{~g}$ ). On days 8 and 9, phospho-Stat 3 immunostaining was highly detected in the decidual cells (Fig. 3h). After rabbit anti-human phospho-Stat3 antibody was replaced with normal IgG, no signals were detected in the uterus on day 9 of pregnancy (Fig. 3i).

\section{Stat3 immunostaining and activation during early pseudopregnancy}

There was a high level of Stat 3 immunostaining in the luminal epithelium and a low level in the glandular epithelium on days 1 and 2 of pseudopregnancy (Fig. 4a). On days 3 and 4, a low level of Stat 3 immunostaining was seen in the luminal epithelium, glandular epithelium and the stromal cells near the lumen (Fig. 4b). On day 5, strong Stat3 immunostaining was detected in the luminal epithelium and the stromal cells near the lumen (Fig. 4c), while strong Stat3 immunostaining was observed only in the luminal epithelium and weak Stat 3 immunostaining was observed in the glandular epithelium and the stromal cells near the lumen on day 6 (Fig. $4 \mathrm{~d}$ ).

There was strong phospho-Stat 3 immunostaining in the luminal epithelium and low levels in the glandular epithelium and the stromal cells near the lumen on day 1 (Fig. 4e). From days 2 to 4 , a low level of phospho-Stat3 immunostaining was seen in the luminal epithelium, glandular epithelium and the stromal cells near the lumen (Fig. 4f). On day 5, strong phospho-Stat3 immunostaining was detected in the nuclei of the luminal epithelium, the stromal cells and glandular epithelium near the lumen (Fig. 4g). On day 6, there were high levels of phosphoStat3 immunostaining in the nuclei of the luminal epithelium and low levels in the stromal cells and the glandular epithelium surrounding the lumen (Fig. 4h).

\section{Stat3 immunostaining and activation under delayed implantation and after activation}

Under delayed implantation, strong Stat3 immunostaining was seen in the luminal epithelium and weak Stat3 immunostaining was seen in the stromal cells near the lumen (Fig. 5a), while phospho-Stat3 immunostaining was barely detected (Fig. 5C). After delayed implantation was terminated by estrogen treatment, high levels of both Stat3 and phospho-Stat 3 immunostaining were detected in the stromal cells immediately surrounding the implanting blastocyst (Fig. 5b,d).

\section{Stat3 immunostaining and activation under artificial decidualization}

In the control uterine horn, there were low levels of Stat3 immunostaining and phospho-Stat3 immunostaining in the stromal cells near the lumen, the glandular epithelium and luminal epithelium (Fig. 6a,c). Under artificial decidualization, strong Stat3 immunostaining was detected in the decidual cells and longitudinal muscle cells (Fig. 6b), while phospho-Stat 3 immunostaining was seen only in the decidual cells (Fig. 6d).

\section{Discussion}

In the present study, Stat3 mRNA expression was highly detected in the luminal epithelium, and both Stat3 immunostaining and phospho-Stat 3 immunostaining were at high levels in the luminal epithelium and underlying stromal cells on day 5 of pregnancy, which precedes embryo implantation in the rat. This pattern of Stat 3 activation in the rat was different from that in mice. In the mouse, Stat3 was localized to the cytoplasm of the luminal epithelium on day 3 of pregnancy. On day 4, Stat3 localization was predominantly to the nuclei of the entire luminal epithelium, and by day 5, Stat3 had relocalized to the cytoplasm in the luminal epithelium (Cheng et al. 2001). Because mouse blastocysts implant on the evening of day 4 (2300-2400 h) (Das et al. 1995), it is of value to examine the activation of Stat3 during this time. However, we found that in the afternoon of day 6 , strong phospho-Stat3 immunostaining was detected in the luminal epithelium although phospho-Stat3 immunostaining in the subluminal stroma was at a low level. Because rat implantation occurs in the evening of day 6 , it seems that phosphoStat3 activation in the luminal epithelium occurs just before implantation.

Nevertheless, Stat 3 activation in the luminal epithelium and underlying stromal cells on the morning of day 5 and at midnight may also be important for uterine receptivity. LIF expression in the rat uterus during the peri-implantation period has not been examined. But LIF is highly expressed in the mouse uterus just before implantation and has been shown to be required for embryo implantation in the mouse (Bhatt et al. 1991, Stewart et al. 1992, Yang et al. 1995). LIF-deficient mice have failures in embryo implantation (Stewart et al. 1992). Song et al. (2000) reported that LIF can only partially cause resumption of implantation in progesterone-primed and delayed implanting mice in the absence of estrogen. However, Chen et al. (2000) found that LIF can substitute for nidatory estrogen and is essential for inducing a receptive uterus. Additionally, the expression of IL-11 is up-regulated in the rat uterus at the initiation of implantation at 5.5 days after mating, while the expression of IL-11 receptor $\alpha$ and gp130 does not change throughout the periimplantation period ( $\mathrm{Li}$ et al. 2001). These data suggest that the activation of Stat3 by LIF and/or IL-11 in the rat uterus may play a key role during embryo implantation. On the other hand, although mice carrying a mutation of gp130 which deleted all Stat-binding sites are viable, the female mice are infertile because of implantation failure, phenocopied LIF-deficient mice (Ernst et al. 2001). Nevertheless, embryos homozygous for the gp130 mutation 
progressively die between 12.5 days postcoitum and term (Yoshida et al. 1996). Furthermore, nuclear localization of Stat3 in day-4 luminal epithelium was not detected in any LIF-deficient mice, indicating that LIF is the principal mediator of Stat3 activation in vivo (Cheng et al. 2001).

Moreover, the activation of Stat3 in the rat uterus during the preimplantation period does not seem to be induced by the presence of active blastocysts because Stat3 activation in the luminal epithelium and underlying stromal cells was also detected on days 5 and 6 of pseudopregnancy. In the rat, there was a high percentage of embryo implantations after cultured or flushed blastocysts were transferred into the uterine lumen on day 5 of pseudopregnancy (Carp et al. 1988). This suggests that Stat3 activation may be required for uterine receptivity.

Stat3 was highly expressed and activated in the decidual cells from days 7 to 9 of pregnancy and under artificial decidualization in the present study, indicating that Stat3 may also be essential for decidualization. Liu and Ogle (2002) reported that Stat3 in the decidua was most abundant during the active period of stromal cell proliferation and decidualization on days 8-10 of pregnancy. In the mouse, Stat3 becomes phosphorylated in uterine tissues in response to oil infusion for inducing decidualization (Hewitt et al. 2002). IL-11 can activate Stat3 (Takeda et al. 1997). Female mice with a null mutation of the IL-11 receptor $\alpha$ are infertile because of defective decidualization (Bilinski et al. 1998, Robb et al. 1998), indicating that IL-11 receptor $\alpha$ signaling at the implantation site appears to be required for decidual development. The action of Stat3 during decidualization may be mediated by IL-11. In addition, oncostatin $M$ produced by decidual cells can stimulate the release of human chorionic gonadotropin (hCG) in humans (Ogata et al. 2000), while hCG is essential for the luteal rescue during the maternal recognition of pregnancy (Duncan 2000). Therefore, how oncostatin $M$ acts during decidualization remains to be determined.

We found that strong immunostaining for both Stat3 and phospho-Stat3 was detected in the embryos from days 5 to 9 of pregnancy. Stat3-deficient embryos showed a rapid degeneration between embryonic days 6.5 and 7.5, although they developed into the egg cylinder stage until embryonic day 6.0, demonstrating that Stat3 is essential for the early development of mouse embryos (Takeda et al. 1997). LIF, LIF receptor and gp130 mRNAs were detected in mouse blastocysts (Nichols et al. 1996). Preimplantation human embryos express LIF and LIF receptor mRNAs (Chen et al. 1999). However, LIF-deficient mouse embryos could develop to term when transferred into wild-type pseudopregnant recipients (Stewart et al. 1992), indicating that LIF-induced activation of Stat3 is not important for embryo development.

In conclusion, the strong level of Stat3 activation in the luminal epithelium and underlying stromal cells during the pre-implantation period in the rat may be essential for establishing uterine receptivity as in mice. Additionally, the high level of Stat3 expression and activation in decidual cells may play an important role during decidualization.

\section{Acknowledgements}

This work was supported by Chinese National Natural Science Foundation grants 30270163, 39825120 and 30330060, and the Special Funds for Major State Basic Research Project (G1999055903).

\section{References}

Akira S, Nishio Y, Inoue M, Wang XJ, Wei S, Matsusaka T, Yoshida K, Sudo T, Naruto M \& Kishimoto T 1994 Molecular cloning of APRF, a novel IFN-stimulated gene factor 3 p91-related transcription factor involved in the gp130-mediated signaling pathway. Cell $7763-71$.

Bhatt H, Brunet LJ \& Stewart CL 1991 Uterine expression of leukemia inhibitory factor coincides with the onset of blastocyst implantation. PNAS 88 11408-11412.

Bilinski P, Roopenian D \& Gossler A 1998 Maternal IL-11R alpha function is required for normal decidua and fetoplacental development in mice. Genes and Development 12 2234-2243.

Carp HJ, Fein A \& Nebel L 1988 Effect of diclofenac on implantation and embryonic development in the rat. European Journal of Obstetrics, Gynecology and Reproductive Biology 28 273-277.

Chapman RS, Lourenco P, Tonner E, Flint D, Selbert S, Takeda K, Akira S, Clarke AR \& Watson CJ 2000 The role of Stat3 in apoptosis and mammary gland involution. Conditional deletion of Stat3. Advances in Experimental and Medical Biology 480 129-138.

Chen HF, Shew JY, Ho HN, Hsu WL \& Yang YS 1999 Expression of leukemia inhibitory factor and its receptor in preimplantation embryos. Fertility and Sterility 72 713-719.

Chen JR, Cheng JG, Shatzer T, Sewell L, Hernandez L \& Stewart CL 2000 Leukemia inhibitory factor can substitute for nidatory estrogen and is essential for inducing a receptive uterus for implantation but is not essential for subsequent embryogenesis. Endocrinology 141 4365-4372.

Cheng JG, Chen JR, Hernandez L, Alvord WG \& Stewart CL 2001 Dual control of LIF expression and LIF receptor function regulate Stat3 activation at the onset of uterine receptivity and embryo implantation. PNAS 98 8680-8685.

Darnell JE Jr 1997 STATs and gene regulation. Science 277 1630-1635.

Das SK, Chakraborty I, Paria BC, Wang XN, Plowman G \& Dey SK 1995 Amphiregulin is an implantation-specific and progesteroneregulated gene in the mouse uterus. Molecular Endocrinology 9 691-705.

Davis S, Aldrich TH, Stahl N, Pan L, Taga T, Kishomoto T, Ip NY \& Yancopoulos GD 1993 LIFR $\beta$ and gp130 as heterodimerizing signal transducers of the tripartite CNTF receptor. Science $\mathbf{2 6 0}$ 1805-1806.

Duncan WC 2000 The human corpus luteum: remodeling during luteolysis and maternal recognition of pregnancy. Reviews of Reproduction 5 12-17.

Ernst M, Inglese M, Waring P, Campbell IK, Bo S, Clay FJ, Alexander WS, Wicks IP, Tarlinton DM, Novak U, Heath JK \& Dunn AR 2001 Defective gp130-mediated signal transducer and activator of transcription (STAT) signaling results in degenerative joint disease, gastrointestinal ulceration, and failure of uterine implantation. Journal of Experimental Medicine 194 189-203.

Gearing DP, Comeau MR, Friend DJ, Gimpel SD, Thut CJ, McGourty J, Brasher KK, King JA, Gillis S, Mosley B, Ziegler SF \& Cosman D 1992 The IL-6 signal transducer gp130: an oncostatin M receptor and affinity converter for the LIF receptor. Science 255 $1434-1437$. 
Hewitt SC, Goulding EH, Eddy EM \& Korach KS 2002 Studies using the estrogen receptor $\alpha$ knockout uterus demonstrate that implantation but not decidualization-associated signaling is estrogen dependent. Biology of Reproduction 67 1268-1277.

Kennedy TG \& Ross HE 1997 Temporal- and hormonal-dependent changes in uterine sensitization for the decidual cell reaction and decidualization in vitro of rat endometrial stromal cells. Journal of Reproduction and Fertility 109 129-136.

Li R, Hartley L \& Robb L 2001 Cloning of rat interleukin 11 and interleukin 11 receptor alpha chain and analysis of their expression in rat uterus in the peri-implantation period. Reproduction 122 $593-600$.

Liu T \& Ogle TF 2002 Signal transducer and activator of transcription 3 is expressed in the decidualized mesometrium of pregnancy and associates with progesterone receptor through protein and protein interactions. Biology of Reproduction 67 114-118.

Nichols J, Davidson D, Taga T, Yoshida K, Chambers I \& Smith A 1996 Complementary tissue-specific expression of LIF and LIFreceptor mRNAs in early mouse embryogenesis. Mechanisms of Development 57 123-131.

Ogata I, Shimoya K, Moriyama A, Shiki Y, Matsumura Y, Yamanaka K, Nobunaga T, Tokugawa Y, Kimura T, Koyama M, Azuma C \& Murata Y 2000 Oncostatin M is produced during pregnancy by decidual cells and stimulates the release of hCG. Molecular Human Reproduction 6 750-757.

Orlando-Mathur CE, Bechberger JF, Goldberg GS, Naus CCG, Kidder GM \& Kennedy TG 1996 Rat endometrial stromal cells express the gap junction genes connexins 26 and 43 and form functional gap junctions during in vitro decidualization. Biology of Reproduction 54 905-913.

Pellegrini S \& Dusanter-Fourt I 1997 The structure, regulation and function of the Janus kinases (JAKs) and the signal transducers and activators of transcription (STATs). European Journal of Biochemistry 248 615-633.
Robb L, Li R, Hartley L, Nandurkar HH, Koentgen F \& Begley CG 1998 Infertility in female mice lacking the receptor for interleukin 11 is due to a defective uterine response to implantation. Natural Medicine 4 303-308.

Song H, Lim H, Das SK, Paria BC \& Dey SK 2000 Dysregulation of EGF family of growth factors and COX-2 in the uterus during the preattachment and attachment reactions of the blastocyst with the luminal epithelium correlates with implantation failure in LIFdeficient mice. Molecular Endocrinology 14 1147-1161.

Stewart CL, Raspar P, Brunet LJ, Bhatt H, Gadi I, Kontgen F \& Abbondanzo SJ 1992 Blastocyst implantation depends on maternal expression of leukemia inhibitory factor. Nature 359 76-79.

Takeda K, Noguchi K, Shi W, Tanaka T, Matsumoto M, Yoshida N, Kishimoto T \& Akira S 1997 Targeted disruption of the mouse Stat3 gene leads to early embryonic lethality. PNAS 94 $3801-3804$.

Yang ZM, Le SP, Chen DB, Cota J, Siero V, Yasukawa K \& Harper MJK 1995 Leukemia inhibitory factor, LIF receptor, and gp130 in the mouse uterus during early pregnancy. Molecular Reproduction and Development 42 407-414.

Yoshida K, Taga T, Saito M, Suematsu S, Kumanogoh A, Tanaka T, Fujiwara $H$, Hirata $M$, Yamagami $T$, Nakahata $T$, Hirabayashi $T$, Yoneda Y, Tanaka K, Wang WZ, Mori C, Shiota K, Yoshida N \& Kishimoto T 1996 Targeted disruption of gp130, a common signal transducer for the interleukin 6 family of cytokines, leads to myocardial and hematological disorders. PNAS 93 407-411.

Received 20 October 2003

First decision 14 January 2004

Revised manuscript received 6 April 2004

Accepted 21 April 2004 